\title{
Autoritarismo no Brasil do presente: bolsonarismo nos circuitos do ultraliberalismo, militarismo e reacionarismo
}

\author{
Maria do Socorro Sousa de Araújo ${ }^{1}$ \\ https://orcid.org/0000-0002-3545-8949
}

\author{
Alba Maria Pinho de Carvalho ${ }^{2}$ \\ https://orcid.org/0000-0002-3500-3792
}

${ }^{1}$ Universidade Federal do Maranhão, Departamento de Serviço Social, Programa de Pós-Graduação em Políticas Públicas, São Luís, MA, Brasil

${ }^{2}$ Universidade Federal do Ceará, Departamento de Ciências Sociais, Programa de Pós-Graduação em Sociologia, Fortaleza, CE, Brasil

\begin{abstract}
Autoritarismo no Brasil do presente: bolsonarismo nos circuitos do ultraliberalismo, militarismo e reacionarismo

Resumo: No presente texto, analisamos o autoritarismo como fenômeno contemporâneo, em âmbito mundial, a expressar-se, fortemente, no Brasil, nos marcos do capitalismo financeirizado. Alicerçadas na análise crítica de estudiosos da realidade brasileira, abordamos o bolsonarismo como expressão do autoritarismo no Brasil do Presente, constituído a partir da convergência do reacionarismo político-cultural, militarismo e ultraliberalismo. Para tanto, fundamentadas em Carvalho (2019), realizamos um recuo na história contemporânea brasileira, até a década de 1990, adentrando nos percursos do ajuste do país ao capitalismo mundializado. A partir desse marco histórico, discutimos a predominância das práticas voltadas ao ajuste financeiro, em meio aos embates pela democracia, com destaque para o Golpe 2016 e para a eleição de Jair Messias Bolsonaro, ápice do Golpe. Sustentamos a tese de que o bolsonarismo é uma expressão contemporânea do autoritarismo no Brasil, constituindo um dilema analítico e um desafio político.
\end{abstract}

Palavras-chave: Bolsonarismo. Autoritarismo. Democracia. Ultraliberalismo. Golpe 2016.

\section{Authoritarianism in Brazil today: bolsonarism in the circuits of ultraliberalism, militarism and reactionaryism}

Abstract: In this text, we analyze authoritarianism as a contemporary phenomenon, worldwide, expressing itself strongly in Brazil, within the framework of financialized capitalism. Based on the critical analysis of scholars on the Brazilian reality, we approach bolsonarism as an expression of authoritarianism in Brazil of the Present, constituted from the convergence of political-cultural reactionism, militarism and ultraliberalism. To this end, based on Carvalho (2019), we made a retreat in contemporary Brazilian history, until the 1990s, entering the paths of the country's adjustment to globalized capitalism. Based on this historical landmark, we discussed the predominance of practices aimed at financial adjustment, amid the clashes for democracy, with emphasis on the 2016 Coup and the election of Jair Messias Bolsonaro, the apex of the Coup. We support the thesis that Bolsonarism is a contemporary expression of authoritarianism in Brazil, constituting an analytical dilemma and a political challenge.

Keywords: Bolsonarism. Authoritarianism. Democracy. Ultraliberalism. Coup 2016.

Recebido em 30.06.2020. Aprovado em 02.08.2020. Revisado em 29.09.2020.

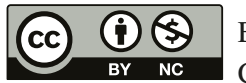

Este é um artigo publicado em acesso aberto (Open Access) sob a licença Creative Commons Attribution NonCommercial, que permite uso, distribuição e reprodução em qualquer meio, sem restrições desde que sem fins comerciais e que o trabalho original seja corretamente citado. 


\section{Introdução}

A pandemia mundial do novo Coronavírus, ou da COVID 19, desencadeou um debate acerca do autoritarismo, focando a relação Estado/Sociedade. Emergem polêmicas em torno de práticas de controle da população, como estratégia de governantes para contenção da disseminação do vírus. Em determinados espaços, questiona-se a legitimidade do controle e sanções de governos, em nome do bem-comum, no sentido de conter o avanço avassalador da pandemia. Em certos países europeus, a população, em meio aos números da tragédia de infectados e mortos, acata e legitima as formas de controle governamental. Já em outros países, segmentos da população rebelam-se, não cumprindo o devido isolamento social, levando os governos à adoção de medidas coercitivas, inclusive com aparato policial. Em nações como a China, primeiro epicentro da pandemia, a população obedeceu rigidamente às determinações do governo e o vírus conseguiu ser controlado ${ }^{1}$.

Entre nós, em terras brasileiras, diferentes segmentos sociais, por motivos qualitativamente distintos, desrespeitam as determinações de isolamento. Inegavelmente, grande parte da população das periferias não tem condições objetivas de ficar em casa, mergulhada nas tramas da pobreza, expressas das mais diferentes formas, desde a informalidade do trabalho até a precarização de condições de moradia e de saneamento. Representantes do capital industrial e comercial rebelam-se contra o isolamento que diminui suas taxas de lucro. $\mathrm{O}$ fato é que, no contexto da pandemia do coronavírus, levantam-se questionamentos sobre a cultura política democrática brasileira, enfatizando a posição do Estado e da própria sociedade. E, paradoxalmente, grupos marcados por práticas fascistas, vão às ruas, questionando o que consideram o autoritarismo das medidas de isolamento social. Em contrapartida, estes grupos agridem profissionais de saúde, avançam contra o Supremo Tribunal Federal (STF), retomando rituais de setores extremistas, no âmbito do fascismo. Assim, a questão do autoritarismo adentra as pautas de discussão da vida brasileira, exigindo reflexões críticas acerca do que denominamos Brasil do Presente, período gestado nos últimos cinco anos, a partir do Golpe de 2016 (CARVALHO et al., 2019, 2020).

A rigor, o autoritarismo é recorrente na história brasileira, inclusive, com longos períodos de ditadura, a exemplo do Estado Novo de Getúlio Vargas (1937-1945) e a Ditadura Civil-Militar, deflagrada em 1964, prolongando-se até meados dos anos 1980. No Brasil do Presente, o autoritarismo, fincado na pesada arquitetura do Golpe de 2016, emerge com novas configurações. Pesquisas desenvolvidas pelo Varieties Democracy (V-DEM) (2020)² indicam que, nesta segunda década do século XXI, práticas democráticas vêm se restringindo no Brasil, passando o país a ocupar o quinto lugar no ranking internacional das nações que mais diminuíram o índice da democracia (LÜHRMANN; MAERZ et al., 2020). Dados de pesquisa do já referido Instituto, especializado no estudo da democracia em nível mundial, revelam que o avanço do autoritarismo vem agravando-se no período relativo ao Governo de Jair Messias Bolsonaro (LÜHRMANN; MAERZ et al., 2020), com a polarização, cada vez mais intensa, entre esquerda e direita. A vida brasileira está marcada pela disseminação do ódio, de tensões permanentes entre os poderes da República, com ataques frontais ao Legislativo e ao Judiciário, por segmentos da extrema-direita bolsonarista. Investidas constantes contra as mídias fazem parte do arsenal de ódio do bolsonarismo, inclusive com episódios de ataques pessoais contra jornalistas, quando no exercício das suas funções.

As práticas autoritárias do bolsonarismo são a culminância de um processo sistemático de ataque às esquerdas, com ênfase no petismo. Merece destaque a cruzada de combate à corrupção no âmbito da LavaJato, que o site The Intercept, do jornalista Glenn Greenwald (2019 apud JOÃO FILHO, 2019), mostrou seu caráter de estratégia política de perseguição às esquerdas. É um cenário marcado por fenômenos de forte teor autoritário: afronta aos direitos humanos e às conquistas de segmentos historicamente discriminados, como indígenas, negros/as, mulheres, comunidade LGBTQ+; exaltação de torturadores e suas práticas violentas brutais, incluindo reivindicações de retorno à Ditadura Militar. As redes sociais constituíram espaços de mobilização das forças de direita, que tomaram as ruas reivindicando o impeachment da presidenta Dilma Rousseff. Em meio aos acordos políticos e jurídicos, institucionaliza-se o Golpe de 2016, deflagrando o governo de Michel Temer. Tais elementos com destaque, particular, para o impeachment e o consequente Golpe jurídico-parlamentar-midiático de 2016, expressam um processo de desconfiguração da democracia e da implementação do autoritarismo, nos marcos da vida brasileira.

Nesse rastro, as bases políticas, forjadas a partir da institucionalização do Golpe de 2016, também nomeado Golpe 16, levaram à emergência, em 2019, de um governo de extrema direita consolidado na eleição 
do Presidente Jair Messias Bolsonaro, conformando o que Carvalho (2019) denomina como bolsonarismo, caracterizado pela composição do ultraliberalismo, do militarismo e do reacionarismo político-cultural.

É nossa intenção adentrar nos meandros do bolsonarismo como uma materialização do autoritarismo contemporâneo no Brasil do Presente. Logo, este artigo consubstancia esse intento, com base em leituras críticas da realidade brasileira. Em nossa discussão, encarnamos a tese, desenvolvida por Carvalho (2019) e Carvalho et al. (2019), de que, para analisar o Brasil do Presente, no contexto do bolsonarismo, impõe-se a necessidade de um recuo na história, tomando como marco os últimos 30 anos, ou seja, de 1990 a 2020. Segundo a autora, neste período, vivencia-se uma confluência complexa e contraditória de dois processos que, estruturalmente, demarcam a tessitura da vida brasileira, quais sejam: a democracia, vinda de meados da década de 1980 e o ingresso do País no ajuste ao capitalismo financeirizado, na década de 1990, até o momento atual (2020).

A partir desse recuo na história, configuramos os desdobramentos do denominado ajuste estrutural brasileiro, em meio aos embates pela democracia, ocorridos, com maior ou menor intensidade, no decorrer das diversas conjunturas do Brasil do Ajuste, com destaque para os ciclos dos governos do Partido dos Trabalhadores, no período de 2003 a 2015 e para o Golpe 2016. Ademais, analisamos a eleição de Jair Messias Bolsonaro, em 2019, aqui considerada como ápice do Golpe e a configuração do bolsonarismo, como fenômeno sociopolítico no Brasil do Presente (CARVALHO, 2019).

Trata-se de um ensaio, formulado no âmbito da pesquisa Reconfigurações da Política de Assistência Social no contexto contemporâneo, ante o desmonte da Seguridade Social no Brasil (2016-2020): expressões peculiares em São Luís do Maranhão ${ }^{3}$, que vem sendo realizada, em nível de pós-doutoramento, a partir de março de 2020, junto ao Programa de Pós-Graduação em Sociologia, na Universidade Federal do Ceará, sob a supervisão da Prof. ${ }^{a}$ Dr. ${ }^{a}$ Alba Maria Pinho de Carvalho. Ademais, constituem parte de debates, estudos e pesquisas desenvolvidos no âmbito do Grupo de Estudos e Avaliação da Pobreza e de Políticas direcionadas à Pobreza (GAEPP), vinculado ao Departamento de Serviço Social (DESES) e ao Programa de Pós-Graduação em Políticas Públicas (PPGPP), da Universidade Federal do Maranhão (UFMA).

Assim, o presente texto, elaborado a partir de pesquisa bibliográfica e seminários de discussão, visa analisar as particularidades do contexto econômico, social e político no Brasil contemporâneo, com destaque para o bolsonarismo.

\section{A contemporaneidade em tempo de pandemia e o necessário recuo analítico: a história imediata como exigência do nosso tempo}

Analisar processos históricos em andamento, ou seja, discutir questões do tempo presente, algumas delas ainda em curso, configura uma prática que os historiadores denominam de interpretação de eventos, sob a forma de uma história imediata. (CHAUVEAU; TÉTARD, 1999). De fato, sem sombra de dúvidas, tal empreitada constitui-se um desafio analítico e uma exigência metodológica.

Em tempos da pandemia mundial de 2020, tal desafio é ainda maior, em decorrência do fato de que, no atual momento, estamos vivendo uma situação excepcional, a colocar em suspenso as atividades que compõem o cotidiano das pessoas, desde as atividades mais elementares, de cunho pessoal ou familiar, às ações coletivas e mais complexas, a envolverem questões sanitárias e sociais, no campo da economia, da política e da cultura.

Nesse sentido, Boaventura de Sousa Santos (2020) sinaliza para a exigência do cuidado, a ser adotado pelos intelectuais, na tentativa de configuração de uma realidade em movimento, num dado contexto de excepcionalidade, como é o caso da atual pandemia. A esse respeito, afirma o autor:

A pandemia confere à realidade uma liberdade caótica, e qualquer tentativa de a aprisionar analiticamente está condenada ao fracasso, dado que a realidade vai sempre adiante do que pensamos ou sentimos sobre ela. Teorizar ou escrever sobre ela é pôr as nossas categorias e a nossa linguagem à beira do abismo. (SANTOS, 2020, p. 13).

Santos (2020) enfatiza que a geração de intelectuais, que nasceu ou cresceu no período após a Segunda Guerra Mundial, acostumou-se a ter um pensamento excepcional em tempos normais. E assim: 
Perante a crise pandêmica, têm dificuldade em pensar a exceção em tempos excepcionais. O problema é que a prática caótica e esquiva dos dias foge à teorização ou exige ser entendida em modo de subteorização. Ou seja, como se a claridade da pandemia criasse tanta transparência que nos impedisse de ler e muitos menos reescrever o que fôssemos registrando no ecrã ou no papel" (SANTOS, 2020, p. 13).

De fato, a civilização do capital na contemporaneidade vive tempos de "excepcional exceção" (SANTOS, 2020). Em meio à uma crise humanitária, que atinge pilares do sistema do capital, o autoritarismo afirma-se nos chamados países democráticos. É emblemático o caso de Donald Trump, nos Estados Unidos, para ficarmos no ilustre campo do G-8, com expressivas encarnações no contexto latino-americano, destacando-se, a tragédia do Brasil bolsonarista. Em suas análises da realidade contemporânea, intelectuais, pesquisadores e militantes tentar circunscrever este instigante momento histórico, conceituando, como fascismo, novo fascismo, fascismo periférico. A esse respeito, bem enfatiza Chauí (2019):

Estamos acostumados a identificar o fascismo com a presença do líder de massas como autocrata. É verdade que, hoje, embora os governantes, não se alcem à figura do autocrata, operam com um dos instrumentos característicos do líder fascista, qual seja, a relação direta com "o povo", sem mediações institucionais e mesmo contra elas. Também, hoje, se encontram presentes outros elementos próprios do fascismo: o discurso de ódio ao outro - racismo, homofobia, misoginia; o uso das tecnologias de informação que levam a níveis impensáveis as práticas de vigilância, controle e censura; e o cinismo ou a recusa da distinção entre verdade e mentira como forma canônica da arte de governar.(CHAUí, 2019, p. 1).

A autora, contudo, não utiliza o termo fascismo para configurar este momento histórico e assim justifica:

No entanto, não emprego esse termo por três motivos: (a) porque o fascismo tem um cunho militarista que, apesar das ameaças de Trump à Venezuela ou ao Irã, as ações de Nathanayu sobre a faixa de Gaza, ou a exibição da valentia do homem armado pelo governo Bolsonaro e suas ligações com as milícias de extermínio, não podem ser identificados com a ideia fascista do povo armado; (b) porque o fascismo propõe um nacionalismo extremado, porém a globalização, ao enfraquecer a ideia do Estado-nação como enclave territorial do capital, retira do nacionalismo o lugar de centro mobilizador da política e da sociedade; (c) porque o fascismo pratica o imperialismo sob a forma do colonialismo, mas a economia neoliberal dispensa esse procedimento usando a estratégia de ocupação militar de um espaço delimitado por um tempo delimitado para devastação econômica desse território, que é abandonado depois de completada a espoliação. (CHAUÍ, 2019, p. 1).

Chauí (2019) em vez de utilizar o termo fascismo ou novo fascismo, denomina o neoliberalismo com o termo totalitarismo, adotando, como referência, as análises da Escola de Frankfurt sobre os efeitos do surgimento da ideia de sociedade administrada. A autora parte da compreensão de que o movimento do capital transforma toda e qualquer realidade em objeto do capital e para o capital, modificando tudo em mercadoria, instituindo um sistema universal de equivalências, próprio de uma formação social baseada na troca pela mediação de uma mercadoria universal abstrata, o dinheiro.

No âmbito desta discussão, Carvalho (2020), Virginia Fontes (2020 apud ENTREVISTA..., 2020) e Santos (2020) destacam um elemento decisivo na compreensão crítica da realidade social: o próprio modo de funcionamento do capitalismo contemporâneo, a acirrar contradições e vulnerabilidades. De fato, esse modelo da economia capitalista está fincado em uma espiral de expansão e crescimento sem fim, com contradições internas de acumulação e circulação, com fluxos crescentes de capital rentista, a procurar valorização, sempre em busca de lucro (HARVEY, 2020). A esse respeito, Harvey destaca que este modelo de uma espiral de expansão ilimitada do capital

torna-se bastante complicado à medida que é elaborado através, por exemplo, das lentes das rivalidades geopolíticas, dos desenvolvimentos geográficos desiguais, das instituições financeiras, das políticas estatais, das reconfigurações tecnológicas e da teia em constante mudança das divisões do trabalho e das relações sociais (HARVEY, 2020, p. 13).

Assim, essa dinâmica global de acumulação do capital, em uma expansão sem limites, com base na extrema tecnologização, mantém-se a partir de uma relação crescente de expropriação da natureza e da força 
de trabalho, com graves consequências ambientais/ecológicas e com uma precarização extrema da chamada nova classe trabalhadora, sem empregos e sem direitos, lançada em formas brutais de informalidade, em nível de uma sobrevivência consumista (CARVALHO, 2020). E, nessa dinâmica, a crise estrutural do capital vem se reproduzindo, neste século XXI, comprometendo a vida social e a própria sobrevivência do planeta no capitalismo contemporâneo.

Nessa perspectiva, Chauí (2019) explicita o porquê da opção em denominar o neoliberalismo como novo totalitarismo. Conforme a autora:

Totalitarismo: porque em seu núcleo encontra-se o princípio fundamental da formação social totalitária, qual seja, a recusa da especificidade das diferentes instituições sociais e políticas que são consideradas homogêneas e indiferenciadas porque são concebidas como organizações. O totalitarismo é a afirmação da imagem de uma sociedade homogênea e, portanto, a recusa da heterogeneidade social, da existência de classes sociais, da pluralidade de modos de vida, de comportamentos, de crenças e opiniões, costumes, gostos e valores. (CHAUÍ, 2019).

E a autora avança nesta sua configuração do neoliberalismo como um novo totalitarismo, deixando claro

\begin{abstract}
Novo: porque, em lugar da forma do Estado absorver a sociedade, como acontecia nas formas totalitárias anteriores, vemos ocorrer o contrário, isto é, a forma da sociedade absorve o Estado. Nos totalitarismos anteriores, o Estado era o espelho e o modelo da sociedade, isto é, instituíam a estatização da sociedade; o totalitarismo neoliberal faz o inverso: a sociedade se torna o espelho para o Estado, definindo todas as esferas sociais e políticas não apenas como organizações, mas, tendo como referência central o mercado, como um tipo determinado de organização: a empresa - a escola é uma empresa, o hospital é uma empresa, o centro cultural é uma empresa, uma igreja é uma empresa e, evidentemente, o Estado é uma empresa. (CHAUÍ, 2019).
\end{abstract}

Conforme a autora, as consequências do novo totalitarismo, nas sociedades contemporâneas, expressam-se nos aspectos social e econômico, político e ideológico. Chauí (2019) ressalta, em relação aos aspectos sociais e econômicos, que a introdução do desemprego estrutural e a terceirização toyotista do trabalho dá origem a uma nova classe trabalhadora denominada de precariado para indicar um novo trabalhador sem emprego estável, sem contrato de trabalho, sem sindicalização, sem direitos trabalhistas e que, por não ser cidadão pleno, tem a mente atormentada pelo medo, pela perda da autoestima e da dignidade, pela constante insegurança.

Ainda segundo a autora, este novo totalitarismo põe fim às duas formas democráticas existentes no modo de produção capitalista: (a) socialdemocracia, com a privatização dos direitos sociais, o aumento da desigualdade e da exclusão; (b) democracia liberal representativa, definindo a política como gestão e não mais como discussão e decisão públicas da vontade dos representados por seus representantes eleitos (CHAUÍ, 2019).

Assim, na discussão de Chauí (2019), os gestores criam a imagem de que são os representantes do verdadeiro povo, da maioria silenciosa com a qual se relacionam, de forma ininterrupta e direta, por meio do Twitter, de blogs e redes sociais - isto é, por meio do digital party -, operando sem mediação institucional, pondo em dúvida a validade dos parlamentos políticos e das instituições jurídicas, promovendo manifestações contra eles. Nessa perspectiva, emerge a judicialização da política, pois os conflitos são resolvidos pela via jurídica e não pela via política propriamente dita. Em outras palavras, sendo o Estado uma empresa, os conflitos não são tratados como questão pública e, sim, como questão jurídica, no melhor dos casos e, como questão de polícia, a resgatar uma histórica alternativa na vida brasileira (CHAUÍ, 2019).

Chauí (2019) considera que os gestores atuam como gangsters mafiosos, que institucionalizam a corrupção, adotam o clientelismo e (re)forçam lealdades. E, como os chefes mafiosos, os governantes também têm os consiglieri, conselheiros, isto é, supostos intelectuais que orientam ideologicamente as decisões e os discursos dos governantes, produzindo, via de regra, discursos de ódio ao diferente, aos socialmente vulneráveis, tais como: imigrantes, migrantes, refugiados, LGBTQ+ e outros. Ademais, esse discurso ideológico torna-se justificativa para práticas de extermínio. E os gestores gangsters transformam os adversários políticos em corruptos, embora a corrupção mafiosa seja adotada, praticamente, como a única regra de governo. Exercem controle sobre o Judiciário, ao dispor de informações sobre os magistrados, em âmbito familiar e profissional, passando a oferecer proteção aos magistrados em troca, de lealdade (CHAUí, 2019). 
Nesse contexto do novo totalitarismo, os gestores perseguem todas as formas e expressões do pensamento crítico e inventam a divisão da sociedade entre o bom povo, que os apoia, e os diabólicos, que os contestam. Por orientação dos consiglieri, pretendem fazer uma limpeza ideológica, social e política e, para isso, desenvolvem uma teoria da conspiração comunista, que seria liderada por intelectuais e artistas de esquerda. (CHAUÍ, 2019).

Essas configurações analíticas de Marilena Chauí (2019) sobre o novo totalitarismo, consubstanciado no contexto de políticas neoliberais e/ou ultraliberais, delineiam preciosas vias para pensar o bolsonarismo como expressão contemporânea do autoritarismo no Brasil do Presente.

\section{Bolsonarismo como uma expressão do autoritarismo brasileiro no século XXI: ultraliberalismo, militarismo e reacionarismo}

Neste final da segunda década do século XXI, o Bolsonarismo constitui um fenômeno sociopolítico, resultante da convergência de forças constitutivas da direita e da extrema-direita no Brasil. A rigor, o Bolsonarismo está para além da figura de Jair Bolsonaro, embora esta figura grotesca e bizarra tenha significados sociopolíticos, trazendo à baila marcas históricas da formação social brasileira e da nossa própria cultura política, materializadas no conservadorismo, no machismo, no racismo, na misoginia, nas discriminações de múltiplas naturezas. Bolsonaro parece bem encarnar a perspectiva colonialista de submissão, elitismo e violência, a atravessar a história do País, reatualizando-se no reacionarismo político-cultural, em pauta no Brasil do Presente.

Em coerência com a chave-analítica circunscrita por Carvalho et al. $(2019,2020)$, de exigência de um recuo histórico na contemporaneidade, é fundamental, no desvendamento do Bolsonarismo, incidir o foco analítico, especificamente, nos percursos da inserção do Brasil ao capitalismo financeirizado, nas últimas três décadas. De fato, um marco histórico é o Ajuste Estrutural Brasileiro, a partir de 1990, a circunscrever a inserção subordinada do Brasil ao capitalismo financeirizado. É o Brasil do Ajuste (1990-2020), em curso, ao longo de três décadas, com diferentes ciclos, com distintas inflexões e particularidades (CARVALHO; GUERRA, 2015).

É decisivo demarcar que, ao longo dos processos de inserção subordinada do Brasil ao capitalismo financeirizado, constitui-se o que chamamos de modelo dependente de Ajuste Estrutural Brasileiro, qual seja, o Modelo Rentista-Neoextrativista. É fundamental compreender esse modelo de ajuste dominante na América Latina e, particularmente no Brasil, entendendo sua estruturação e dinâmica ao longo da história contemporânea.

Como bem circunscrevem Carvalho, Milanez e Guerra (2018), o modelo rentista-neoextrativista é a encarnação da nossa inserção geopolítica dependente, em tempos contemporâneos. Tal modelo é uma resultante da composição orgânica entre o rentismo, isto é, o capital financeiro e suas formas exorbitantes de lucros via juros e o capital vinculado ao neoextrativismo, a acumular riquezas pela via da expropriação, do agronegócio e da mineração, com base na intensa mercantilização de commodities agrícolas e minerais. Trata-se da imbricação do financismo e do neoextrativismo, numa poderosa combinação em que os donos das finanças e os ruralistas, os segmentos do agronegócio e da mineração, ditam os rumos da vida brasileira.

A implementação do modelo rentista-neoextrativista no Brasil contemporâneo apresenta diferentes inflexões nos distintos ciclos de ajuste. Merece especial destaque os ciclos de ajuste petistas que viabilizam o modelo rentista-neoextrativista pela via da ideologia da conciliação de classes, na perspectiva de viabilizar uma regulação dos conflitos classistas, amenizando e desarticulando o confronto de forças. De fato, esses governos, na condição de governos de ajuste ao capitalismo financeirizado, investem no que pode ser denominado um pacto de classes com distintas estratégias: privilegiamento dos interesses do capital rentista e do capital vinculado ao neoextrativismo; atendimento pontual de demandas imediatas de setores extremamente empobrecidos da massa trabalhadora e de segmentos assalariados; absorção, no aparelho de Estado, de segmentos da burocracia sindical e da direção dos movimentos sociais. Em verdade, configura-se a contraditoriedade na condução política dos governos petistas, delineando o chamado social-liberalismo petista (CARVALHO; RODRIGUES JÚNIOR, 2019).

Em meados da segunda década do século XXI, no âmbito de um cenário desfavorável à expansão desse modelo rentista-neoextrativista, verifica-se a ruptura do pacto de classes pelas elites. É o esgotamento da versão petista do modelo rentista-neoextrativista de ajuste. De fato, a ruptura desse pacto de classe, pelas elites do capital, está na base da crise contemporânea brasileira, chão histórico do Golpe 2016. Indiscutivelmente, a 
ruptura do pacto pelas elites, com a deflagração do Golpe, cria as condições para impor o neoliberalismo mais violento e brutal (CARVALHO; RODRIGUES JÚNIOR, 2019). É o ultraliberalismo nas chamadas políticas de austeridade, oficialmente implementadas no Brasil com o Golpe 16, a instaurar o governo ilegítimo de Michel Temer, iniciando um novo ciclo de ajuste, nomeado "submissão radical ao financismo e desmonte de direitos pela via do golpe" (CARVALHO; MILANEZ; GUERRA, 2018, p. 16). De fato, nos marcos do ultraliberalismo, imbricado ao autoritarismo, o Governo Temer implementa uma nova versão do modelo de ajuste rentistaneoextrativista de cunho ultraliberal, de privilegiamento do capital estrangeiro, de superexploração da força de trabalho, de espoliação das riquezas nacionais, do fundo público, do processo de desmontes dos direitos sociais e trabalhistas (CARVALHO et al., 2019).

Este governo, forjado a partir do Golpe 2016, instaura, assim, um projeto autoritário, conservador, alicerçado pelo desmonte dos direitos sociais, pela desestruturação do Sistema de Seguridade Social no País ${ }^{4}$, pela redefinição do orçamento público, com a implementação da Emenda Constitucional ${ }^{\circ} 95$, que instituiu, de forma abrupta e arbitrária, o Novo Regime Fiscal (NRF) para a União, pelos próximos vinte anos. Em um contexto de aprofundamento da pobreza e das desigualdades sociais no Brasil, a referida Emenda - originalmente, PEC 241/2016, denominada PEC da Morte - estabelece um teto de gastos para com as despesas primárias, destinadas a cada um dos poderes, limitando o crescimento anual dos gastos públicos à taxa de inflação de 2016 (BRASIL, 2016), colocando em questão a sustentação das políticas sociais, num processo de inflexão do financiamento público.

A rigor, o ano de 2016 consubstancia uma nova época histórica na vida brasileira, instaurando um tempo de autoritarismo, em meio às configurações formais da democracia representativa, na República Brasileira. Trata-se de um ataque frontal à democracia no Brasil, atingindo as instituições e permeando a própria cultura política.

É importante considerar que esta entrada do Brasil em um ciclo autoritário-conservador, a partir de um golpe de Estado em formato contemporâneo, não é um fato isolado no contexto mundial. Balestrin (2018), no âmbito do que denomina debate pós-democrático, circunscreve quatro eventos, ocorridos em 2016, em diferentes lugares do mundo, a questionarem os limites da democracia representativa, liberal e ocidental: na Inglaterra, o plebiscito que revelou a aprovação, pela maioria da população, da saída da União Europeia; na Colômbia, a rejeição, pela maioria da população, do referendo de acordo de paz com as FARC (Fuerzas Armadas Revolucionarias de Colômbia); nos Estados Unidos, a vitória inesperada de Donald Trump; e, no Brasil, o processo de impeachment de Dilma Rousseff. Enfatiza a referida autora:

Cada qual à sua maneira, tais acontecimentos evidenciam a emergência de discursos abertamente autoritários, anti-humanistas e antidemocráticos; sua eventual legitimação pelo voto popular, partidos políticos e/ou lideranças populistas; e a utilização das instituições democráticas para a fragilização, minimização ou ruptura da própria democracia (BALESTRIN, 2018, p. 149).

Assim, tendo em vista o ciclo iniciado com o Golpe 2016 e o consequente Governo Temer, os autores Carvalho, Milanez e Guerra (2018, p. 28) avaliam:

Nos últimos anos da segunda década do século XXI - mais precisamente 2016, 2017, 2018 - vivemos um tempo de radicalização conservadora sob a égide do rentismo, que desmonta direitos, que dilui pactos e marcos regulatórios e que desmonta políticas públicas, produzindo um contexto de (des)proteção social, insegurança e imprevisibilidade, que impõe a resistência como exigência histórica.

Inegavelmente, essa pesada e autoritária arquitetura de desmonte da democracia brasileira culmina com um governo de extrema-direita, nos marcos do Bolsonarismo, a intensificar novas configurações do autoritarismo no Brasil do Presente. Carvalho et al. (2019) sinaliza que não se pode perder de vista que, ao longo da segunda década dos anos 2000, mais precisamente a partir de 2015, durante o processo de deflagração da crise brasileira, ocorre, no País, a emergência da chamada nova direita brasileira, em sua peculiar e complexa composição, com suas distintas configurações. De fato, a nova direita no Brasil começa a ganhar visibilidade pública nas manifestações de 2013, descobrindo o caminho das ruas e ganhando crescentes espaços nas redes sociais. A rigor, a nova direita brasileira revela uma singular composição, a ser compreendida no cenário do País. 
A nova direita configura-se, a partir da adoção e difusão de postulados neoliberais, em versões doutrinárias, dogmáticas, com a utilização de práticas e discursos reacionários, de ódio e de desqualificação da esquerda, atacando os chamados comunistas, em uma verdadeira batalha ideológica, pautada nos fundamentos do mentor Olavo de Carvalho. Esta nova direita, formatada em interpretações doutrinárias da ideologia neoliberal, junta-se a uma direita forjada no fundamentalismo religioso de igrejas neopentecostais, a pregar a necessidade de salvaguarda da moral e dos bons costumes, em meio a práticas intolerantes, conservadoras, que justificam o discurso de ódio e a adoção da violência, numa batalha para livrar o Brasil de práticas consideradas mundanas, principalmente, aquelas relativas à não preservação da família dita tradicional e seus respectivos valores morais. E, ainda, nesta composição de novas direitas, afirma-se o militarismo e o justicialismo, a pregar um retorno à Lei de Talião, propagando, como saída para a questão da segurança pública, a violência armada, a pena de morte e o extermínio, expresso na máxima - bandido bom é bandido morto (CARVALHO et al., 2019).

Em verdade, trata-se de uma composição de direitas intercruzadas, a ocupar a cena do presente, constituindo esta nova direita brasileira que, em meio a um sentimento difuso e vazio de mudança, a alastrar-se no País, transforma um militar reformado e político medíocre, sem nenhuma projeção, há quase três décadas na Câmara dos Deputados, nos grotões do chamado baixo clero, em mito, a encarnar a mudança, em um País, em crise. De fato, a emergência de Bolsonaro, nas conexões virtuais, se dá em um País em crise, a emergir da ruptura, pelas próprias elites, dos chamados pactos de classes, deixando as esquerdas, que apostaram nesse canto de sereia, sem chão... É um País abalado, com a democracia em desmanche, nos rastros de um Golpe institucional. Avalia Carvalho (2020):

Este "paradoxo Bolsonaro/mudança" só se torna possível na "terra arrasada" de um Brasil atingido por um Golpe das elites, que deixa as forças progressistas e as esquerdas na defensiva, tragadas pelo ódio, sistematicamente construído pelo conluio das elites com o Judiciário e sedimentado pela mídia (CARVALHO, 2020, p. 4).

É neste contexto de crise, de avanço das direitas e ódio às esquerdas, que é urdido o Bolsonarismo, como uma configuração sociopolítica de extrema-direita que "articula ultraliberalismo dependente, militarismo autoritário, mesclado com justicialismo da violência e reacionarismo político-cultural, eivado de um moralismo religioso" (CARVALHO, 2019, p. 30). E, assim, explicita Carvalho, em suas análises: o ultraliberalismo dependente consubstancia um agravamento da agenda de ajuste do Governo Temer, a efetivar as chamadas políticas de ajuste fiscal e de austeridade, significando, na prática, privatizações, cortes de gastos públicos e contrarreformas para desonerar a economia, num linguajar típico dos agentes do mercado; o militarismo autoritário, mobilizado na cruzada da anticorrupção, em busca da garantia dos chamados interesses da Pátria, aglutinando um crescente segmento de militares, no interior do governo, permeando os diferentes Ministérios do Poder Executivo; judicialismo pela via da violência, com o recrudescimento do Estado de Exceção. Por fim, o reacionarismo político-cultural, que beira a um fascismo sociocultural, empreendendo uma guerra ideológica de retomada de valores tradicionais, religiosos e pré-democráticos, com a cega convicção de que os grandes problemas do país são "problemas morais" (CARVALHO, 2019, 2020).

O Bolsonarismo, como uma composição de alto risco, vem inserindo o Brasil em um novo colonialismo, retomando a condição de subordinação aos interesses dos países centrais nesta ordem do capitalismo financeirizado, sobretudo dos EUA. Ao mesmo tempo, joga o País no obscurantismo, prisioneiro de amarras reacionárias e desmonta quaisquer controles democráticos. E retoma a marcha autoritária querendo impor, em matizes contemporâneas, valores e práticas do fascismo.

\section{Considerações finais}

Ao longo das reflexões e análises, aqui empreendidas, sinalizamos para um fenômeno contemporâneo, em nível mundial, a expressar-se fortemente no Brasil do Presente: o avanço do autoritarismo, nos marcos do capitalismo financeirizado, fincado em políticas ultraliberais. São discursos e práticas a constituírem, nos dizeres de Chauí (2019), o neoliberalismo totalitário. Implica na articulação de forças de direita e extrema- 
direita, utilizando estratégias, intencionalmente programadas, que mesclam intervenções ilegítimas e ilegais no espaço virtual, nos marcos das fake news, com intervenções de minorias radicalizadas que, trazem para as ruas, a ideologia e a estética fascistas. Na contemporaneidade brasileira, nesse final da segunda década do século XXI, o autoritarismo consubstancia-se no Bolsonarismo e sua composição de alto risco.

Assim, em terras brasileiras, neste primeiro semestre de 2020, vive-se uma dupla pandemia: a pandemia mundial do coronavírus e a pandemia nacional do Bolsonarismo. Esta dupla pandemia implica um agravamento da questão social brasileira, a atingir as classes trabalhadoras e, de modo especial, os que habitam às margens da sociedade.

Como expressão de uma tendência mundial, o futuro é incerto e, extremamente, inseguro. No dizer de Mészáros (2015), é este o "fardo do nosso tempo histórico", a exigir uma luta intransigente por uma democracia radical, capaz de garantir o exercício cotidiano da emancipação humana.

\section{Referências}

BALESTRIN, L. O debate pós-democrático no séc. XXI. Revista Sul-americana de Ciência Política, Pelotas, v. 4, n. $2,2018$.

BRASIL. Proposta de emenda à constituição nº 241-A, de 2016. Altera o Ato das Disposições Constitucionais Transitórias, para instituir o Novo Regime Fiscal, e dá outras providências. Brasília, DF, Câmara dos Deputados, 2016. Disponível em: https://www.camara.leg. br/proposicoesWeb/prop_mostrarintegra?codteor=1495741. Acesso em: 27 jun. 2020.

CARNEIRO, A. M. F. et al. Política de Assistência Social no período 1988-2018: construção e desmonte. Revista Ser Social, Brasília, v. 21, n. 44, p. 29-47, 2019.

CARVALHO, A. M. P de. Bolsonarismo como fenômeno político no Brasil do Presente: uma composição de risco, um desafio à luta política. In: SEMINÁRIO VIRTUAL PAPIIT, 2020. Anais [...]. Fortaleza, 2020.

CARVALHO, A. M. P. et al. A crise capitalista, o avanço da direita no continente latino-americano e os desafios para a resistência. In: JORNADA INTERNACIONAL DE POLÍTICAS PÚBLICAS, 9, 2019, Maranhão. Anais [...]. São Luís: MA, 2019.

CARVALHO, A. M. P de. Desmonte dos direitos da classe trabalhadora: assistentes sociais no combate ao conservadorismo. In: ENCONTRO DE ASSISTENTES SOCIAIS NO MARANHÃO, 40, 2019, Maranhão. Anais [...]. São Luís: MA, 2019.

CARVALHO, A. M. P de.; GUERRA, E. C. O Brasil no século XXI nos circuitos da crise do capital: o modelo brasileiro de ajuste no foco da crítica. Revista de Políticas Públicas, São Luís, v. 19, n. 1, p. 41-60, 2015.

CARVALHO, A. M. P de.; MILANEZ, B.; GUERRA, C. E. Rentismo-neoextrativismo: a inserção dependente do Brasil nos percursos do capitalismo mundializado (1990-2017). In: RIGOTTO, R. M. et al. Tramas para Justiça Ambiental: diálogos e saberes e práxis emancipatórias. Fortaleza: Edições UFC, 2018.

CARVALHO, A. M. P de; RODRIGUES JÚNIOR, N. dos S. Modelo de ajuste nos governos petistas em meio à ideologia da conciliação de classes: chão histórico do Golpe de 2016 no Brasil Contemporâneo. Revista Em Pauta, Rio de Janeiro, v. 17, p. 274-291, 2019.

CHAUÍ, M. Neoliberalismo: a nova forma do totalitarismo. A Terra é redonda, [S. 1.], 6 out. 2019. Disponível em: https://aterraeredonda. com.br/neoliberalismo-a-nova-forma-do-totalitarismo/. Acesso em: 27 jun. 2020.

CHAUVEAU, A.; TETARD, P. Questões para a história do presente. Bauru: EDUSC, 1999.

ENTREVISTA: Coronavírus e a crise do capital. Associação dos Docentes da Universidade Federal do Espírito Santo, Espírito Santo, 28 abr. 2020. Disponível em: https://adufes.org.br/portal/noticias/28-andes/3425-entrevista-coronavirus-e-a-crise-do-capital.html. Acesso em: 25 abr. 2020.

HARVEY, D. Política anticapitalista em tempos do COVID-19. In: HARVEY, D. et al. (org.). Coronavírus e a luta de classes. Brasil: Editora Terra sem amos, 2020. p.13-24.

JOÃO FILHO. A Lava Jato usou o Judiciário para fins políticos. The Intercept, 16 jul. 2019. Disponível em: https://theintercept. com/2019/06/16/vaza-jato-corrupcao-sergio-moro-politica-dallagnol/?comments=1. Acesso em: 25 abr. 2020.

LÜHRMANN, A.; MAERZ, S. F. et al. Autocratization Surges: Resistance Grows, democracy report 2020. V- Dem Institute varieties of democracy, Los Angeles, USA, mar. 2020. Disponível em: https://www.v-dem.net/media/filer_public/f0/5d/f05d46d8-626f-4b208e4e-53d4b134bfcb/democracy_report_2020_low.pdf. Acesos em: 25 abr. 2020.

MÉSZÁROS, István. O Desafio e o fardo de tempo histórico. São Paulo: Boitempo Editorial,2015.

SANTOS, B. de S. A Cruel pedagogia do vírus. São Paulo: Boitempo Editorial, 2020.

ZIBECHI, R. Coronavírus: a militarização das crises. In: HARVEY, David et al. (org.) Coronavírus e a luta de classes. Brasil: Editora Terra sem amos. 


\section{Notas}

1 Zibechi (2020), ao analisar o caso da China, argumenta que o mundo está diante de um novo modelo de gestão de crise, que parece ser ratificado pelo Ocidente. Assim, afirma que as práticas, intensas e extensas, usualmente adotadas na China, intensificaram-se, multiplicaram-se e configuram-se "como um gigantesco panóptico militar e sanitário, que limita a população a viver trancada e sob permanente vigilância” (ZIBECHI, 2020, p. 31). Nesses termos, para além das questões afetas à saúde da população, o autor trabalha três questões centrais em relação às práticas de manejo da epidemia, quais sejam: as práticas de controle desenvolvidas pela China são extremamente úteis para as classes dominantes em todo o planeta, visando manter a população sobre vigilante controle e domínio permanente nos períodos de profundas crises econômicas, sociais e políticas, decorrentes da própria crise terminal do capitalismo; as elites estão utilizando a pandemia como um laboratório social, com a finalidade de ampliar o controle sobre a população, em escala micro e macro regional, combinando ações de controle local, com outras mais amplas, através da internet e da denominada videovigilância; as distintas populações, ao redor do mundo, não dispõem, ainda, de conhecimento acerca de como enfrentar essas estratégias de controle de grandes massas populacionais, ao tempo em que confluem com práticas de militarização das sociedades, mediante levantes e revoltas.

2 Estudo elaborado pelos pesquisadores Anna Lührmann e Staffan I. Lindberg, publicado em março de 2020, no site https://www.vdem.net/en/, mantido pela organização não governamental Varieties of Democracy (V-Dem), entidade ligada à Universidade de Gotemburgo, Suécia. Os pesquisadores, com base em estudos realizados no âmbito do V-Dem, visando medir o índice de democracia em âmbito mundial, apontam que, atualmente, 92 países adotam regimes autoritários, enquanto 87 adotam regimes democráticos. Segundo a referida pesquisa, então publicada em março de 2020, os cinco países mais democráticos do mundo são Dinamarca, Estônia, Suécia, Suíça e Noruega, enquanto os cinco países mais autoritários são Eritreia, Coreia do Norte, Arábia Saudita, Iêmen e Síria (LÜHRMANN; MAERZ et al., 2020).

3 A proposta investigativa, ora citada, constitui-se num desdobramento de uma pesquisa regional realizada no contexto do projeto: Avaliando a implementação do Sistema Único de Assistência Social na Região Norte e Nordeste: significado do SUAS para o enfrentamento à pobreza nas regiões mais pobres do Brasil, mediante cooperação acadêmica entre pesquisadores integrantes dos seguintes programas de pós-graduação: Programa de Pós-Graduação em Políticas Públicas da Universidade Federal do Maranhão; Programa de Pós-Graduação em Sociologia da Universidade Federal do Ceará, Programa de Pós-Graduação em Serviço Social da Universidade Estadual do Ceará e Programa de Pós-Graduação em Serviço Social da Universidade Federal do Pará.

4 A respeito do desmonte da Seguridade Social, particularmente, da Política de Assistência Social no contexto do Governo Temer, ver Carneiro et al. (2019).

\section{Maria do Socorro Sousa de Araújo}

contato.socorro@gmail.com

Doutora em Políticas Públicas pela Universidade Federal do Maranhão (UFMA)

Professora Associada do Departamento de Serviço Social da Universidade Federal do Maranhão (UFMA)

\section{UFMA}

Avenida dos Portugueses, 1966 - Vila Bacanga

São Luís - MA - Brasil

CEP: 65080-805

\section{Alba Maria Pinho de Carvalho}

albapcarvalho@gmail.com

Doutora em Sociologia pela Universidade Federal do Ceará (UFCE)

Pós-doutoramento em Sociologia Política pela Universidade de Coimbra

Professora Associada do Departamento de Ciências Sociais da Universidade Federal do Ceará (UFCE)

\section{(UFC)}

Avenida da Universidade, 2853 - Benfica)

Fortaleza - CE - Brasil

CEP:60020-181 


\section{Agradecimentos}

Não se aplica.

Agência financiadora

Não se aplica.

Contribuições das autoras

Manuscrito elaborado em coautoria, trata de tema de estudo e pesquisa realizada por ambas as autoras. Todo o conteúdo do artigo foi elaborado em conjunto e integra as atividades realizadas no âmbito do Estágio Pós-Doutoral da autora Maria do Socorro Sousa de Araújo, sob a supervisão da autora Alba Maria Pinho de Carvalho.

Aprovação por Comitê de Ética e consentimento para participação

Não se aplica.

Consentimento para publicação

Consentimento das autoras.

Conflito de interesses

Não há conflito de interesses. 